\title{
Effects of Maytenus ilicifolia on reproduction and embryo-fetal development in Wistar rats
}

\author{
A.L. Cunha-Laura ${ }^{1}$, S.A. Auharek ${ }^{1}$, R.J. Oliveira ${ }^{2}$, J.M. Siqueira ${ }^{3}$, \\ M.C. Vieira ${ }^{4}$, V.S. Leite ${ }^{5}$ and L.C. Portugal ${ }^{1}$ \\ ${ }^{1}$ Centro de Ciências Biológicas e da Saúde, \\ Universidade Federal de Mato Grosso do Sul, Campo Grande, MS, Brasil \\ ${ }^{2}$ Faculdade de Medicina, Universidade Federal de Mato Grosso do Sul, \\ Campo Grande, MS, Brasil \\ ${ }^{3}$ Campus Centro-Oeste Dona Lindu, Universidade Federal de São João Del Rei, \\ Divinópolis, MG, Brasil \\ ${ }^{4}$ Faculdade de Ciências Agrárias, Universidade Federal da Grande Dourados, \\ Dourados, MS, Brasil \\ ${ }^{5}$ Centro de Ciências Biológicas, Universidade Estadual de Londrina, \\ Londrina, PR, Brasil \\ Corresponding author: A.L. Cunha-Laura \\ E-mail: andrea.laura@ufms.br
}

Genet. Mol. Res. 13 (2): 3711-3720 (2014)

Received September 16, 2013

Accepted January 21, 2014

Published May 9, 2014

DOI http://dx.doi.org/10.4238/2014.May.9.16

ABSTRACT. Maytenus ilicifolia (Celastraceae), popularly known as espinheira-santa, is a native plant from the Atlantic forest and is commonly used in popular medicine to treat inflammation and as an abortifacient. To evaluate the effects of $M$. ilicifolia on pregnant rats during the organogenic period (T1) or throughout the gestational period (T2), an extract obtained using an acetone-water mixture at a 70:30 ratio was administered via gavage at a dose of $15.11 \mathrm{mg} \cdot \mathrm{kg}^{-1} \cdot \mathrm{day}^{-1}$ over 2 treatment periods (T1 and T2). No clinical signs of maternal toxicity were observed. Term fetuses did not present malformations or anomalies as the number of implantations, reabsorptions, live, and dead fetuses were similar to the control group. In conclusion, $M$. ilicifolia 
hydroacetonic extract is non-toxic to pregnant rats and appears to not interfere with the progress of embryo-fetal development.

Key words: Maytenus ilicifolia; Toxicology; Reproduction; Embryo-fetal development

\section{INTRODUCTION}

Maytenus ilicifolia Mart. (Celastraceae) is a plant native to the Atlantic forest (Jorge et al., 2004); its leaves are popularly known as espinheira-santa and are used to treat dyspepsia and gastric ulcers (Carlini, 1988; Leite et al., 2010). In southwestern Brazil, the roots of M. ilicifolia, known as cancorosa, are added to alcoholic drinks and terere, a common local beverage with a bitter taste (Nunes et al., 2003). The presence of phenolic metabolites, such as tannins, flavonoids, and triterpenes, has been observed in the leaves (Vilegas et al., 1995; Queiroga et al., 2000; Jorge et al., 2004; Radomski et al., 2004; Leite et al., 2010) and its gastroprotective effect has been associated with the presence of tri- and tetra-glycoside flavonoid derivatives (Leite et al., 2010). Previous studies performed by Vargas et al. (1991) and Horn and Vargas (2003) showed that the aqueous extract of M. ilicifolia did not have genotoxicity, but did have a significant antimutagenic effect in Salmonella/microsome assays. Moreover, M. ilicifolia is used as a contraceptive and abortifacent by women in Paraguay, Argentina, and Southern Brazil (Hnatyszyn et al., 1974; Arenas and Azorero, 1977). In addition, Montanari and Bevilacqua (2002) demonstrated that M. ilicifolia has estrogenic activity in pregnant mice and exhibited an uterotropic effect, suggesting that the compound interferes with uterine receptivity to an embryo (Montanari and Bevilacqua, 2002). Despite its widespread popular usage, toxicological information for M. ilicifolia on reproductive performance remains limited. The possible toxic effects resulting from the interaction of $M$. ilicifolia extract with organs involved in cell proliferation as well as in embryonic tissues should be determined.

Medicinal plants play an important role in public health, particularly in developing countries, where it is thought that the utilization of plants with therapeutic action is safe (Mossi et al., 2009). However, it is well-established in the literature that several plant drugs commonly used as folk medicine have adverse effects on fertility in rats and show teratogenic effects. Thus, we investigated the effect of $M$. ilicifolia on reproduction and embryo-fetal development. Pregnant rats were exposed to 2 periods of treatment: during the organogenic period (from days 6-15 of pregnancy) and throughout the gestational period (from days 1-20 of pregnancy). The M. ilicifolia single dose used in this experiment was based on the average consumption in the population. An acetone-water ratio of 70:30 was used for extraction of the compounds present in the leaves. This extraction method showed a higher rate of yield $(\mathrm{w} / \mathrm{w})$ when compared to hydroethanolic extraction. Moreover, the thin layer chromatography profile showed higher enrichment of flavonoid derivatives (Wagner and Bladt, 2001).

\section{MATERIAL AND METHODS}

\section{Extract preparation}

The leaves of M. ilicifolia were collected in Dourados (MS, Brazil), and identified 
by E. Jacomassi. A voucher specimen was deposited in the DDMS Herbarium (registration number 901). Dried leaves were percolated in 70:30 acetone: $\mathrm{H}_{2} \mathrm{O}(\mathrm{v} / \mathrm{v})$, and the solvent was eliminated under reduced pressure. The resulting brown, amorphous residue, which was the crude extract, weighed $9.1 \mathrm{~g}(22.8 \%$, w/w yield $)$. This extract was stored in amber glass at room temperature in a desiccator. A similar extraction method was employed with a 70:30 ratio of ethanol: $\mathrm{H}_{2} \mathrm{O}$ and yielded a $7.6 \% \mathrm{w} / \mathrm{w}$ extract.

Both extracts were dissolved in methanol at a 1:1 ratio, and then $20-\mu \mathrm{L}$ samples were compared using thin layer chromatography covered with silica gel; the ratio of the glycoside flavonoids ethyl acetate: formic acid: acetic acid: $\mathrm{H}_{2} \mathrm{O}$ eluent was 100:11:11:26. A natural product/polyethylene glycol reagent was followed by ultraviolet measurement at $365 \mathrm{~nm}$ (Wagner and Bladt, 2001).

\section{Animals}

Female rats were mated with male rats and gestational day 0 (GD0) was determined if spermatozoa were present in the vagina. Animals were housed in a standard animal facility at a controlled temperature $\left(22^{\circ} \mathrm{C}\right)$ and photoperiod $(12 \mathrm{~h}$ light, $12 \mathrm{~h}$ dark) with access to water and rodent food ad libitum. All procedures and protocols followed approved guidelines for the ethical treatment of animals according to the Ethics Committee in Animal Experimentation of the Universidade Federal de Mato Grosso do Sul (Protocol \#115/2006).

\section{Experimental procedure}

Mated females were randomly assigned to 2 experimental groups and exposed to $M$. ilicifolia in different windows of treatment time: during the organogenic period (from days 6-15 of pregnancy, $\mathrm{T} 1, \mathrm{~N}=10$ ) or throughout the gestational period (from days 1-20 of pregnancy, $\mathrm{T} 2, \mathrm{~N}=10$ ). The dose used in this experiment corresponded to that commonly used in folk medicine (Balbach, 1986). Females in the M. ilicifolia-treated group received 15.11 $\mathrm{mg} \cdot \mathrm{kg}^{-1} \cdot$ day $^{-1}$ of the extract suspended in $0.5 \mathrm{~mL}$ distilled water via gavage during treatment ( $\mathrm{T} 1$ and $\mathrm{T} 2)$. The control group $(\mathrm{N}=10)$ received only $0.5 \mathrm{~mL} / \mathrm{kg}$ vehicle.

Females were weighed on gestational days (GD) 1, 6, 15, and 20. To evaluate maternal toxicity, water and food intake were recorded during treatments. These values were calculated as the difference between the amount of food or water on the morning of one day and the amount of food or water remaining in the morning of the following day. On GD20, females were sacrificed by $\mathrm{CO}_{2}$ inhalation. To examine the reproductive capacity of female rats, laparotomy was performed and uterine horns were removed. The number of implants, resorptions, and dead and live fetuses was recorded. The ovaries were also observed and the corpora lutea were counted. The rate of preimplantation loss was calculated as: number of corpora lutea number of implantations x 100/number of corpora lutea. Postimplantation loss rate was calculated as: number of implantation - number of live fetuses x 100/number of implantations. The maternal kidney, spleen, and liver were also weighed.

The offspring group was randomly divided into 2 subgroups, each consisting of half of the litter. The first was fixed in Bodian's solution for visceral examination, which was performed using the incisions/microdissection method proposed by Barrow and Taylor (1969) for the thorax and abdomen and using the strategic incisions proposed by Wilson (1965) for the 
study of the head. Classification of visceral alterations was based primarily on the methods of Taylor (1986) and Manson and Kang (1994) and alterations proposed by Oliveira et al. (2009). The second subgroup was reserved for skeletal examination using the Alizarin Red technique described by Staples and Schnell (1964). The degree of ossification was evaluated using the parameters proposed by Aliverti et al. (1979). Examination of visceral and skeletal fetuses was performed using a dissecting stereomicroscope. For qualitative data and frequencies, the litter was considered the unit basis as recommended in the literature (Haseman and Hogan, 1975; Manson et al., 1982). However, to quantify visceral and skeletal malformations, the fetus was used as the basic unit according to Moreira et al. (2005).

\section{Statistical analysis}

Values are reported as means $\pm \mathrm{SE}$ and data were analyzed using one-way analysis of variance followed by Tukey's post-hoc test using the GraphPad Prism (version 5; Graph-Pad Software Inc.; San Diego, CA, USA). The significance level was set at $\mathrm{P}<0.05$.

\section{RESULTS}

No difference was observed between the body weights of control and treated animals for the 2 pregnancy periods during which the $M$. ilicifolia hydroacetonic extract was administered (Figure 1). In addition, there was no significant weight gain or loss observed during the experiment (Table 1). Moreover, no maternal deaths, locomotor alterations, diarrhea, or piloerection, which are clinical signs of maternal toxicity, were observed in any of the groups investigated. However, other criteria indicative of maternal toxicity were evident with respect to changes in water and food consumption. Compared with controls, the T1 group showed significantly reduced $(\mathrm{P}<0.05)$ water consumption from GD8-14 (Figure 2A), which corresponds to the period of $M$. ilicifolia extract exposure. Food consumption was significantly reduced $(\mathrm{P}<0.05)$ at GD16 in the T1 group and at GD2, GD5, GD6, GD7, and GD11 in the $\mathrm{T} 2$ group compared with controls (Figure $2 \mathrm{~B}$ ).

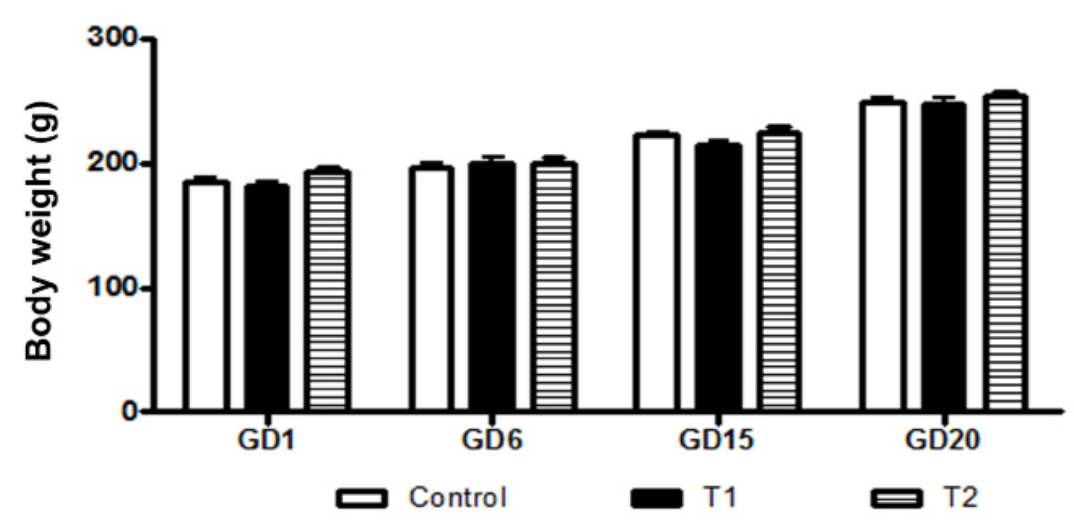

Figure 1. Maternal body weight of pregnant Wistar rats treated with extract of Maytenus ilicifolia from early gestation (GD1) through to late gestation (GD20) in the different treatment windows (T1: days 6-15 of pregnancy and T2: days 1-20 of pregnancy). $\mathrm{P}>0.05$. 
Table 1. Maternal toxicity variables after treatment with extract of Maytenus ilicifolia in Wistar rats from 6-15 (T1) or 1-20 (T2) days of pregnancy.

\begin{tabular}{lccc}
\hline & & Experimental groups \\
\cline { 2 - 4 } Maternal variables & Control $(\mathrm{N}=10)$ & $\mathrm{T} 1(\mathrm{~N}=10)$ & $\mathrm{T} 2(\mathrm{~N}=10)$ \\
\hline Body weight gain $(\mathrm{g})$ & $64 \pm 4.3$ & $65.6 \pm 5.4$ & $59.5 \pm 3.7$ \\
Liver: absolute weight $(\mathrm{g})$ & $11.6 \pm 0.3$ & $10.4 \pm 0.3$ & $10.6 \pm 0.3$ \\
Relative weight $(\mathrm{g})$ & $4.2 \pm 0.001$ & $4.2 \pm 0.001$ & $4.6 \pm 0.001$ \\
Kidney*: absolute weight (g) & $0.76 \pm 0.03$ & $0.8 \pm 0.02$ & $0.75 \pm 0.02$ \\
Relative weight (g) & $0.31 \pm 0.0001$ & $0.3 \pm 0.0001$ & $0.32 \pm 0.0001$ \\
Spleen absolute weight (g) & $0.52 \pm 0.01$ & $0.46 \pm 0.02$ & $0.5 \pm 0.02$ \\
Relative weight (g) & $0.2 \pm 0.0001$ & $0.2 \pm 0.0001$ & $0.2 \pm 0.0001$ \\
Uterine weight (g) & $3.9 \pm 0.3$ & $4.2 \pm 0.2$ & $3.9 \pm 0.3$ \\
Ovary weight (mg)** & $82.3 \pm 0.003$ & $83.4 \pm 0.003$ & $82.3 \pm 0.005$ \\
Corpora lutea (N) & $10.7 \pm 0.7$ & $11.8 \pm 0.4$ & $11.3 \pm 0.4$ \\
Implantation sites & $10.5 \pm 0.7$ & $1.8 \pm 0.4$ & $10.6 \pm 0.09$ \\
Reabsorptions & $2.3 \pm 0.8$ & $100(118 / 118)$ & $1.8 \pm 0.7$ \\
Implantation rate (\%) & $98.13(105 / 107)$ & 0 & $93.8(106 / 113)$ \\
Preimplantation loss (\%) & 1.87 & $13 \pm 2$ & 6.2 \\
Postimplantation loss (\%) & $21.9 \pm 8.4$ & $87 \pm 2$ & $15.2 \pm 6$ \\
Birth rate (\%) & $78 \pm 8$ & $85 \pm 2$ \\
\hline Results are reported & & 0.2 \\
\end{tabular}

Results are reported as means \pm standard error. $\mathrm{P}>0.05 . *$ Left and right kidney average weight. ** Left and right ovary average weight.

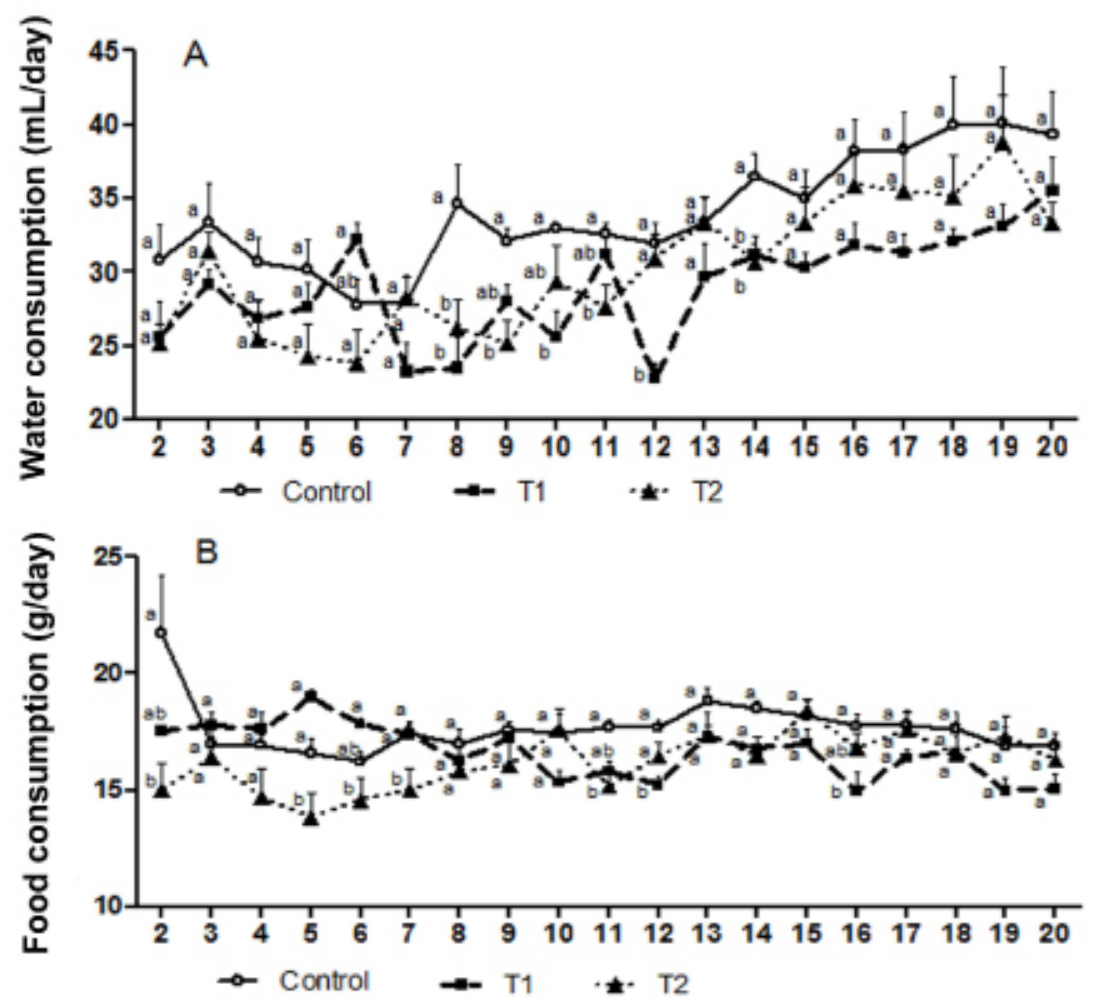

Figure 2. Water (A) and food (B) consumption by pregnant Wistar rats treated with extract of Maytenus ilicifolia $(\mathrm{T} 1=$ days $6-15$ of pregnancy and $\mathrm{T} 2=$ days $1-20$ of pregnancy). Different letters for the same day indicate significant differences $(\mathrm{P}<0.05)$. 
Table 1 shows the maternal toxicity variables of the control, T1, and T2 M. ilicifoliaexposed groups. The absolute and relative weights of the liver, kidneys, spleen, and ovary in both experimental groups investigated ( $\mathrm{T} 1$ and $\mathrm{T} 2)$ were similar $(\mathrm{P}>0.05)$. In addition, macroscopic analysis of these organs revealed no morphological changes, such as color, size, texture, or cysts. No significant alterations were observed in the number of corpora lutea, implantation sites, resorptions, pre- and post-implantation losses, and birth rate for all groups investigated. Thus, $M$. ilicifolia gestational exposure did not alter physiological and intrauterine conditions related to reproduction and fetal development.

Table 2 summarizes the fetal variables after gestational treatments with M. ilicifolia hydroacetonic extract. The number of live and dead fetuses per group as well as average size and weight of the fetuses were similar $(\mathrm{P}>0.05)$ between control and M. ilicifolia-exposed animals. No significant visceral abnormalities were observed in the offspring of different experimental groups. Macroscopic analysis of the fetuses and the urogenital system was normal in all groups investigated (Figure 3). In all animals examined, there were no skeletal abnormalities in the fetuses exposed to M. ilicifolia (Figure 4).

Table 2. Fetal variables after treatment with extract of Maytenus ilicifolia in Wistar rats from 6-15 (T1) or 1-20 (T2) days of pregnancy.

\begin{tabular}{llrl}
\hline & & \multicolumn{2}{c}{ Experimental groups } \\
\cline { 2 - 4 } Fetal variables & Control & T1 & T2 \\
\hline Live fetuses (N) & $8.2 \pm 1$ & $10.3 \pm 0.4$ & $8.8 \pm 1$ \\
Dead fetuses (N) & $2.5 \pm 1$ & $1.5 \pm 0.2$ & $2.5 \pm 1$ \\
Fetuses size (cm) & $3.5 \pm 0.1$ & $3.4 \pm 0.1$ & $3.6 \pm 0.08$ \\
Fetuses weight (g) & $2.7 \pm 0.1$ & $2.5 \pm 0.02$ & $2.7 \pm 0.1$ \\
\hline
\end{tabular}

Results are reported as means \pm standard error. $\mathrm{P}>0.05$.
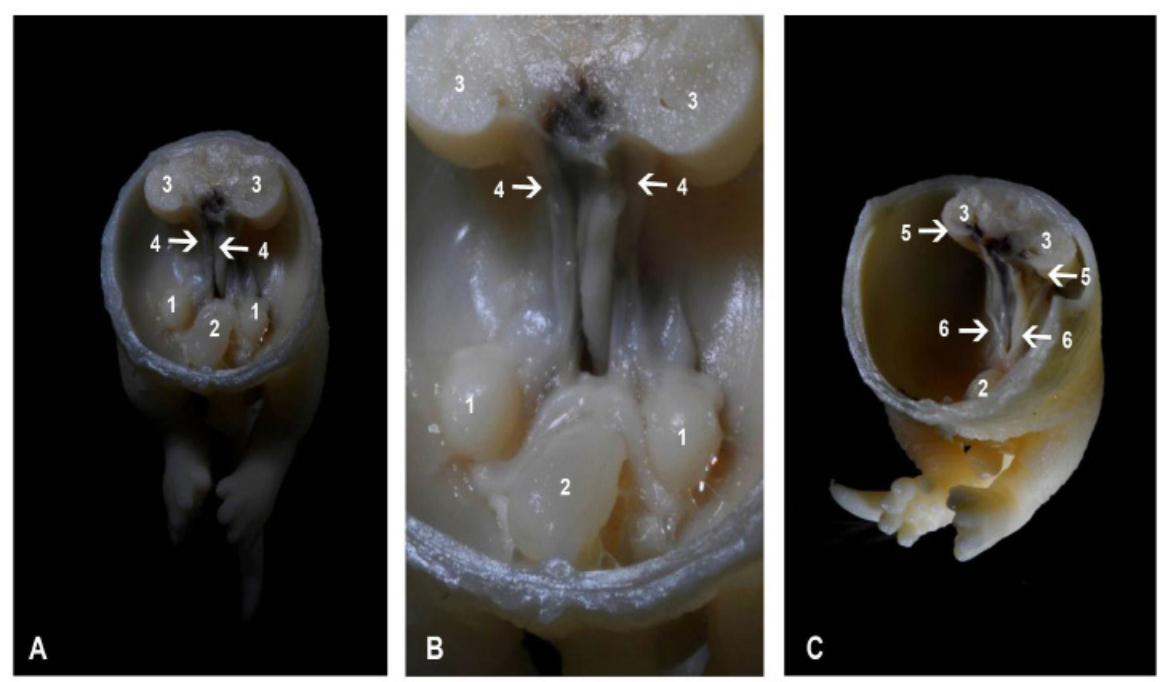

Figure 3. Pelvic incisions of male (A and $\mathbf{B}$ ) and female (C) fetuses exposed to Maytenus ilicifolia from 1-20 days of pregnancy (T2). Normal morphology of the urogenital system was observed: $1=$ testes, $2=$ bladder, $3=$ kidney, $4=$ ureter, $5=$ ovary, $6=$ uterine horn. 


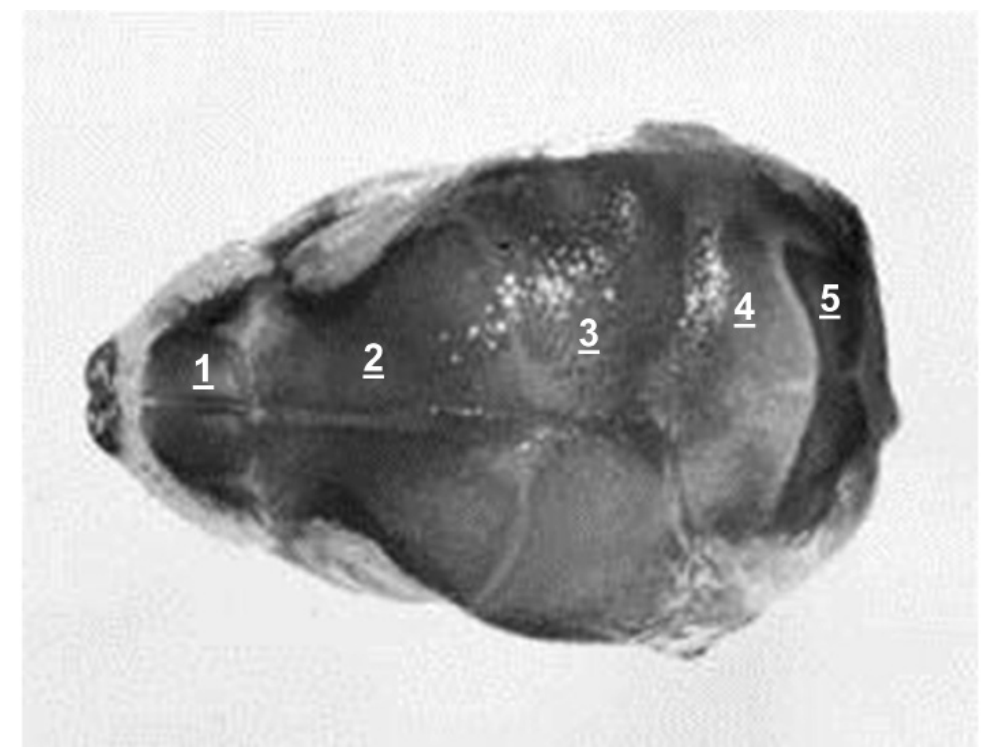

Figure 4. Skeletal analyses of the head of fetuses exposed to Maytenus ilicifolia from 1-20 days of pregnancy. Normal ossification process in the offspring was observed. Lane 1 = nasal; lane 2 = frontal; lane 3 = parietal; lane $4=$ interparietal; lane 5 = supraoccipital.

\section{DISCUSSION}

The leaves of M. ilicifolia are used in traditional medicine to treat dyspepsia and gastric ulcers; antiulcerogenic effects have also been reported. However, the mechanism of action remains unknown (Carlini, 1988; Leite et al., 2001, 2010; Baggio et al., 2012). The leaves of M. ilicifolia contain triterpenes (Itokawa et al., 1991), flavonoid glycosides and catechin derivatives (Leite et al., 2010). In addition, an M. ilicifolia lyophilized aqueous infusion was used for antiulcerogenic evaluation in several biological models. According to phytochemical analyses, flavonoids, glycosides, and catechins were the main compounds observed in the infusion (Leite et al., 2001, 2010).

During pregnancy, multiple agents can interfere with normal development of the embryo, leading to functional and/or morphological alterations. The intensity of the teratogenic effects depends on several factors, including the maternal-fetal genotype, stage of embryonic development, time of exposure to the substance (Spritzer et al., 2001), and mutagenic events such as chromosomal aberrations and non-disjunction (Oliveira et al., 2009). In this study, we evaluated the effects of M. ilicifolia hydroacetonic extract on female reproductive performance and embryo-fetal development. Because an infusion prepared from M. ilicifolia leaves is popularly used by South American women to provoke abortion (Hnatyszyn et al., 1974; Arenas and Azorero, 1977), we investigated M. ilicifolia exposure in pregnant Wistar rats at a dose similar to that used by women.

In general, aqueous preparations such as tea are used in folk medicine; however, at pharmacies (galenic pharmacies), more appropriate formulations include hydroethanolic compounds such as tincture. The use of hydroethanolic tincture may not be the most appropriate 
medicine. Ginkgo biloba is an example of this. Most clinical efficacy studies with G. biloba have been conducted using a standardized water acetone extract, while the alcoholic extract is not recommended for consumption because of the presence of undesirable compounds (Sticher, 1993). Mixtures of acetone and water have also been suggested as suitable solvents for extracting phenolic constituents.

This is the first report in which an extract of M. ilicifolia obtained from an aqueous acetone mixture has been used in a pregnancy model. This extract yielded more weight than hydroethanolic extract. In addition, the thin layer chromatography profile showed prominent spots with retentions (Rf) comparable to flavonoid glycosides (Wagner and Bladt, 2001). Because there were no maternal deaths, changes in locomotor activity, piloerection, diarrhea, or vaginal blood loss in any group, administration of $M$. ilicifolia extract to pregnant rats is concluded to be not toxic. Changes in water and food consumption are also clinical signs indicating drug toxicity (Manson and Kang, 1994). Although there was a reduction in water (during organogenesis) and food consumption in the $\mathrm{T} 1$ group and in food consumption on some days in the T2 group, these effects appeared to be transient since no differences were observed regarding body weight and weight gain in all groups investigated. Another indication of the lack of toxicity was the absence of alterations in organ weights in the treated groups (Damasceno et al., 2002). In addition, this study confirms earlier findings that $M$. ilicifolia does not produce toxic symptoms in mice at doses up to $1000 \mathrm{~g} / \mathrm{kg}$ (Montanari and Bevilacqua, 2002).

Investigations performed in the present study provide important biometric data related to the ovary weights and the number of corpora lutea, which remained unchanged following M. ilicifolia treatment. Thus, pregnant rats may have showed similar hormone production, and thus, the maternal hormonal environment did not differ between treatments. Ovarian weight is largely dependent on the number and volume of corpora lutea because they are the largest structures in this organ (Waynforth, 1971). The corpora lutea are the main source of progesterone secretion (Kato et al., 1979), and an increase in volume during pregnancy and its growth is correlated with increased secretion of progesterone and 20-hydroxy-progesterone (Uchida et al., 1970), hormones that are essential for maintaining pregnancy. In rats, unlike in humans, the corpora lutea remain active throughout the gestational period (Keller, 2006).

Our study showed that in contrast to the hypothesis of Montanari and Bevilacqua (2002), M. ilicifolia does not interfere with uterine receptivity to the embryo. Differences in the experimental results may be explained by the different sensitivities between the species and methods of preparing the botanical extracts (Damasceno et al., 2002). Specifically, using M. ilicifolia, Radomski et al. (2004) found higher concentrations of phenolic compounds and density of $M$. ilicifolia leaves in plants cultivated with direct sun exposure compared to those grown under controlled light and environmental conditions. In addition, significant variation in tannin concentration observed in different $M$. ilicifolia populations suggests a correlation between environmental parameters and tannin concentration in this species (Mossi et al., 2009). However, our results confirm the findings of Oliveira et al. (1991) indicating that treatment with $M$. ilicifolia does not alter the fertility of female rats during pregnancy and that the potential teratogenic effects were not adverse.

The number of implantation sites did not differ between groups, indicating that M. ilicifolia exposure did not affect the implantation process. In this study, no alteration in embryo viability markers was observed, including implants ratio, pre- and post-implantation loss per group ratio, or birth rate. In addition, the dose tested in the present study showed no direct teratogenic effects since the live fetuses showed normal development (Cunha-Laura et al., 
2013) with no visceral or skeletal malformations. The size of the fetus, including body weight and placenta, were similar in all experimental groups, indicating that the treatments did not affect the availability of nutrients needed for maintaining maternal metabolism and fetal development. Our results reveal that the maternal reproductive capacity was not affected by $M$. ilicifolia exposure.

In conclusion, this study provides evidence that $M$. ilicifolia exposure during the organogenic period or throughout gestation is nontoxic and does not interfere with embryo-fetal development or with maternal reproductive parameters.

\section{ACKNOWLEDGMENTS}

Research financially supported by the Brazilian Foundations: FUNDECT-MS and CNPq. J.M. Siqueira and M.C. Vieira were supported by a CNPq research grant.

\section{REFERENCES}

Aliverti V, Bonanomi L, Giavini E, Leone VG, et al. (1979). The extent of fetal ossification as an index of delayed development in teratogenic studies on the rat. Teratology 20: 237-242.

Arenas P and Azorero RM (1977). Plants of common use in Paraguayan folk medicine for regulating fertility. Econ. Bot. 31: 298-301.

Baggio CH, Freitas CS, Twardowschy A, dos Santosa AC, et al. (2012). In vivo/in vitro studies of the effects of the type II arabinogalactan isolated from Maytenus ilicifolia Mart. ex Reissek on the gastrointestinal tract of rats. $Z$. Naturforsch. C 67: 405-410.

Balbach A (1986). A Flora Nacional na Medicina Doméstica. 17th edn. EDEL, São Paulo.

Barrow MV and Taylor WJ (1969). A rapid method for detecting malformations in rat fetuses. J. Morphol. 127: 291-305.

Carlini EA (1988). Estudos de Ação Antiulcera Gástrica de Plantas Brasileiras: Maytenus ilicifolia (espinheira santa) e Outras. CEME/AFIF, Brasília.

Cunha-Laura AL, Oliveira RJ, Barros ALC and de Siqueira JM (2013). Maternal exposure to Cochlospermum regium: a toxicological evaluation. Rev. Bras. Farmacog. 23: 374-378.

Damasceno DC, Volpato GT, Sartori TC, Rodrigues PF, et al. (2002). Effects of Annona squamosa extract on early pregnancy in rats. Phytomedicine 9: 667-672.

Haseman JK and Hogan MD (1975). Selection of the experimental unit in teratology studies. Teratology 12: 165-171.

Hnatyszyn O, Arenas P, Moreno AR and Rondina RVD (1974). Estudio fitoquímico preliminar de plantas medicinales paraguayas I Plantas reguladoras de la fecundidad segun la medicina folklorica. Rev. Soc. Cient. Paraguai 14: 23-57.

Horn RC and Vargas VM (2003). Antimutagenic activity of extracts of natural substances in the Salmonella/microsome assay. Mutagenesis 18: 113-118.

Itokawa H, Shirota O, Ikuta H and Morita H (1991). Triterpenes from Maytenus ilicifolia. Phytochemistry 30: 3713-3716.

Jorge RM, Leite JP, Oliveira AB and Tagliati CA (2004). Evaluation of antinociceptive, anti-inflammatory and antiulcerogenic activities of Maytenus ilicifolia. J. Ethnopharmacol. 94: 93-100.

Kato H, Morishige WK and Rothchild I (1979). A quantitative relation between the experimentally determined number of conceptuses and corpus luteum activity in the pregnant rat. Endocrinology 105: 846-850.

Keller KA (2006). Development and Reproductive Toxicology, 2nd edn. Informa Healthcare, New York.

Leite JP, Rastrelli L, Romussi G, Oliveira AB, et al. (2001). Isolation and HPLC quantitative analysis of flavonoid glycosides from Brazilian beverages (Maytenus ilicifolia and M. aquifolium). J. Agric. Food Chem. 49: 3796-3801.

Leite JPV, Braga FC, Romussi G and Persoli RM (2010). Constituents from Maytenus ilicifolia leaves and bioguided fractionation for gastroprotective activity. J. Braz. Chem. Soc. 21: 248-254.

Manson JM, Zenick H and Costlow RD (1982). Teratology Test Methods for Laboratory Animals. In: Principles and Methods of Toxicology (Hayes AW, edn.). Raven Press, New York, 141-184.

Manson JM and Kang YJ (1994). Test Methods for Assessing Female Reproductive and Developmental Toxicology. In: Principles and Methods of Toxicology (Hayes AW, edn.). Raven Press, New York, 989-1037.

Montanari T and Bevilacqua E (2002). Effect of Maytenus ilicifolia Mart. on pregnant mice. Contraception 65: 171-175.

Moreira CQ, Faria MJ, Baroneza JE, Oliveira RJ, et al. (2005). Developmental exposure to fenproporex: reproductive and 
morphological evaluation. Hum. Exp. Toxicol. 24: 397-402.

Mossi AJ, Mazutti M, Paroul N, Corazza ML, et al. (2009). Chemical variation of tannins and triterpenes in Brazilian populations of Maytenus ilicifolia Mart. Ex Reiss. Braz. J. Biol. 69: 339-345.

Nunes GP, da Silva MF, Resende UM and de Siqueira JM (2003). Plantas medicinais comercializadas por raizeiros no Centro de Campo Grande, Mato Grosso do Sul. Rev. Bras. Farmacog. 13: 83-92.

Oliveira MG, Monteiro MG, Macaubas C, Barbosa VP, et al. (1991). Pharmacologic and toxicologic effects of two Maytenus species in laboratory animals. J. Ethnopharmacol. 34: 29-41.

Oliveira RJ, Salles MJ, da Silva AF, Kanno TY, et al. (2009). Effects of the polysaccharide beta-glucan on clastogenicity and teratogenicity caused by acute exposure to cyclophosphamide in mice. Regul. Toxicol. Pharmacol. 53: 164-173.

Queiroga CL, Silva GF, Dias PC, Possenti A, et al. (2000). Evaluation of the antiulcerogenic activity of friedelan-3beta-ol and friedelin isolated from Maytenus ilicifolia (Celastraceae). J. Ethnopharmacol. 72: 465-468.

Radomski MI, Wisniewski C, Curcio GR and Rachwal MG (2004). Caracterização de ambientes de ocorrência natural e sua influência sobre o peso específico e o teor de polifenóis totais de folhas de espinheira santa (Maytenus ilicifolia Mart.). Braz. J. Medicinal Plants 6: 36-43.

Spritzer DT, Sanseverino MTV and Schuler FL (2001). Manual de Teratogênese. Universidade Federal do Rio Grande do Sul, Porto Alegre.

Staples RE and Schnell VL (1964). Refinements in rapid clearing technic in the koh-alizarin red s method for fetal bone. Stain Technol. 39: 61-63.

Sticher O (1993). Quality of Ginkgo preparations. Planta Med. 59: 2-11.

Taylor P (1986). Practical Teratology. Academic Press, New York.

Uchida K, Kadowaki M, Nomura Y, Miyata K, et al. (1970). Relationship between ovarian progestin secretion and corpora lutea function in pregnant rats. Endocrinol. Jpn. 17: 499-507.

Vargas VM, Guidobono RR and Henriques JA (1991). Genotoxicity of plant extracts. Mem. Inst. Oswaldo Cruz 86 (Suppl 2): $67-70$.

Vilegas JHY, Lanças FM and Filho Antoniosi NR (1995). High temperature capillary GC analysis of phytopreparations of "Espinheira Santa" (Maytenus ilicifolia M. and Maytenus aquifolium M. - Celastraceae), a Brazilian antiulcer plant. Chromatographia 40: 341-344.

Wagner H and Bladt S (2001). Plant drug analysis: A thin layer chromatography atlas. 2dn edn. Springer, Berlin.

Waynforth HB (1971). Changes in the volume of rat coprus luteum during pregnancy and after surgical interference with the uterus and placenta. Acta Endocrinol. (Copenh) 66: 296-302.

Wilson JG (1965). Methods for Administering Agents and Detecting Malformation in Experimental Animal. In: Teratology Principles and Techniques (Wilson JC and Warkany J, eds.). University of Chicago Press, Chicago, 262-277. 